\title{
OS CONFLITOS MORAIS ENFRENTADOS PELOS JUIIZES EM DEMANDAS DE SAÚDE: $O$ CASO DOS TRIBUNAIS FEDERAIS BRASILEIROS
}

The moral conflicts faced by judges concerning health related claims: the case of Brazilian federal courts

${ }^{1}$ Universidade Federal do Rio de Janeiro. Rio de Janeiro/RJ, Brasil. E-mail: jcarloszebulum@gmail.com

Recebido: 28/12/2016. Revisado: 08/06/2017. Aprovado: 24/07/2017. 


\section{RESUMO}

No campo da filosofia do direito, é muito comum o debate sobre as possíveis conexões entre o direito e a moral. Os juízes com jurisdição em saúde debruçam-se frequentemente sobre importantes questões morais que devem ser enfrentadas para que seja dada uma solução ao feito. Nessas ocasiões, os juízes podem experimentar situações de conflito e decidem premidos pelas próprias convicções morais, que nem sempre estarão de acordo com a solução apontada pela simples aplicação da lei. Neste artigo, nos propomos a averiguar como os tribunais federais brasileiros vêm apreciando as questões de natureza moral nas demandas de saúde, preocupando-nos, mais especificamente, com os conflitos morais experimentados pelos magistrados. Para atingir nossa meta, selecionamos três importantes questões com reconhecido potencial de desafiar as convicções morais dos magistrados e corriqueiramente enfrentadas em demandas judiciais de saúde no âmbito dos tribunais do país, e verificamos como estas questões vêm sendo decididas nos tribunais regionais federais. Atentamos principalmente à argumentação utilizada pelos juízes em suas decisões, para então concluirmos pela existência ou não dos referidos conflitos.

\section{Palavras-Chave}

Conflitos Morais; Direito à Saúde; Judicialização da Saúde.

\section{ABSTRACT}

In the field of philosophy of law the debate about the possible connections between law and morality is very common. Judges with jurisdiction over health matters often address important moral issues that must be considered in order to provide a solution to the facts. On these occasions, judges may experience situations of conflict, once they will have to decide pressed by their own moral convictions, which will not always be in accordance with the solution pointed out by the simple application of the law. In this article, we propose to investigate how Brazilian federal courts have been appreciating questions of moral nature in health related demands, concerned more specifically with the moral conflicts experienced by magistrates. In order to achieve our goal, we selected three important issues with recognized potential to challenge the moral convictions of magistrates, commonly faced in health claims in the courts around the country, and we verified how these issues are being decided in the federal regional courts, focusing mainly on the arguments used by the judges in their decisions, in order to conclude whether such conflicts exist or not.

\section{Keywords}

Health Judicialization; Moral Conflicts; Right to Health.. 


\section{Introdução}

O debate entre as possíveis conexões entre a moral ${ }^{1}$ e o direito é velho conhecido dos filósofos, e importantes delimitações já foram estabelecidas entre um e outro campo teórico. Não há dúvida de que os juízes, frequentemente, se debruçam sobre importantes questões morais, que devem, portanto, ser enfrentadas pelo magistrado antes que este possa dar uma solução ao feito. Assim, devemos, inicialmente, definir o que devemos entender como uma "questão moral". Trata-se de questões que provocam um questionamento íntimo acerca dos princípios e das convicções pessoais de

${ }^{1}$ Como leciona Maria Clara Dias, ética e moral, em suas origens, podem ser consideradas expressões sinônimas. Ética tem sua origem no termo grego éthicos, que foi traduzido para o latim como moralis, expressão da qual deriva o termo moral. 0 radical grego ethos apresenta dois sentidos distintos: o primeiro, êthos, diz respeito às faculdades do caráter, e assim, a ética poderia ser entendida como o estudo das faculdades do caráter. Já o segundo sentido, éthos, diz respeito aos costumes, sendo que a tradução de éthicos por moralis encontra suas bases nesta segunda acepção, e deixaria de lado, portanto, a discussão das questões relativas ao caráter. Assim, a ética, na tradição grega, preocupa-se em traçar diretrizes para que possamos desfrutar de uma vida plena, ditando regras que estabelecem a relação do cidadão para consigo mesmo e para com os demais. A moral, tal como é compreendida modernamente, envolve o conjunto de regras ou princípios que orientam a vida social, ou ainda, que prescrevem nosso modo de agir frente às demais pessoas. A partir dessa distinção, que é adotada por alguns autores modernos, como Habermas e Hegel, a moral restringiria seu âmbito de aplicação, e questões referentes à vida privada, que não interferem no bem-estar comum ou nos deveres relativos ao outro, já não pertenceriam à alçada da moral. Optamos, no entanto, tal como faz a referida autora, por admitir as expressões ética e moral como sinônimas, abarcando, assim, as duas acepções acima vistas. Portanto, para nossos objetivos, as chamadas questões morais são aquelas que dizem respeito à interioridade do ser humano, a seu caráter, a sua essência (que, via de regra, dá origem ao âmago do agir, à intenção que irá orientar seus atos, sua conduta, seus hábitos e costumes), sem qualquer restrição no que diga respeito à esfera privada ou a interferência no bem-estar comum. (DIAS, Maria Clara. Sobre nós: expandindo as fronteiras da moralidade. Rio de Janeiro: Pirilampo, 2016).

${ }^{2}$ Tais questões, quando submetidas à apreciação de qualquer pessoa (incluídos os juízes), provocam um juízo de censura ou de aprovação, de certo ou de errado, de justo ou de injusto, que bem caracteriza o discurso ou argumentação moral. Não comportam, por outro lado, valoração do tipo verdadeiro ou falso - como seria o caso de uma asserção da física ou da matemática -, mas sim um juízo de valor, de acordo com princípios morais de cada um. Todas as pessoas, de maneira geral, ainda que mais ou menos reflexivamente, têm suas opiniões sobre o aborto, a eutanásia, a educação dos filhos etc., e as expressam sob forma de um discurso de natureza prescritiva, sobre como agir, como ser justo, correto ou sensato. No entanto, não raro essas opiniões são manifestadas sem maiores preocupações e sem que decorram, verdadeiramente, de uma reflexão profunda e isenta sobre o tema, e não representam uma mera projeção das emoções e convicções pessoais sobre os acontecimentos da vida. Em muitos casos, as pessoas ficam até impacientes quando questionadas sobre a coerência de sua orientação: elas simplesmente separam o "certo" do "errado", o "justo" do "injusto", e "não querem ser perturbadas por dúvidas ou insinuações de incoerência”. (DWORKIN, Ronald. A justiça de toga. São Paulo: Martins Fontes, 2010.) Evidentemente, não é esta a postura que se espera de um juiz ao enfrentar questões dessa natureza, em primeiro lugar por ter o dever imposto pela Constituição Federal de fundamentar suas decisões; em segundo lugar, porque aprecia essas questões como um antecedente lógico da questão de mérito, que pode dizer respeito à vida, à liberdade ou à saúde de outrem. Portanto, sua responsabilidade ao se manifestar sobre as mesmas é indiscutivelmente maior, e exige uma reflexão mais cuidadosa e ponderada. Isso não quer dizer que deva sair em busca de respostas definitivas, com fundamentos capazes de convencer a todos, até porque isso será de todo impossível em se tratando de temas que não admitem, como já visto, asserções do tipo "verdadeiro" ou "falso", mas sim juízos de valor profundamente arraigados às convicções pessoais de cada um. Podemos identificar como um exemplo de questão dessa natureza na área da saúde a situação em que, não raro, o juiz é provocado para decidir se um paciente idoso, com quadro clínico grave, já internado em hospital da rede privada, deve ou não ser transferido com urgência a hospital público especializado, onde poderá receber melhor atendimento. Ocorre que, segundo o laudo médico, a transferência coloca em risco a própria vida do paciente. 
cada um, e que podem provocar reações totalmente diferentes, dependendo de quem as avalia, de sua sensibilidade, de seu caráter, de sua ideologia, de suas crenças, etc.

Em importante debate doutrinário, Richard A. Posner e Ronald Dworkin abordaram a questão do enfrentamento de questões morais pelos juízes. O primeiro defende que tais questões devem ser ignoradas pelos juízes, que dispõem melhores recursos para atingir seus objetivos; segundo Posner $^{3}$, na Inglaterra o direito é uma disciplina autônoma, e tais questões são resolvidas, em grande parte, pela interpretação de textos autorizados, que consistem em leis, regulamentações e decisões judiciais, sendo certo que nenhuma dessas fontes incorpora uma teoria moral. Defendendo posicionamento oposto, Dworkin ${ }^{4}$ adverte que, se os juízes são obrigados a lidar com questões morais, como dizer que devem resolvê-las através da história, da economia, da álgebra ou de qualquer outra técnica que não a moral?

Ao enfrentar essa recorrente questão, Dworkin descreve o direito como um verdadeiro ramo da moralidade ( $a$ branch of moralit $y^{5}$ ), então como um sistema de regras autônomo que, eventualmente, pode entrar em situação de confronto com a moral. Para tornar mais clara sua tese, $D$ workin ${ }^{6}$ utiliza-se de uma metáfora: concebe a moralidade, em sua forma mais geral, como uma árvore, em que o direito seria um galho da moralidade política; esta, por sua vez, seria um galho de uma moral pessoal mais abrangente; e esta última, por fim, um galho de uma teoria ainda mais abrangente, a teoria do bem viver. Dworkin observa que não se pode tomar o Direito e a moral como sistemas separados, sem conexões entre si. Segundo o autor, há uma constante interação entre esses domínios, e nenhuma teoria sobre as relações entre direito e moral, ao presumir a separação entre estes dois sistemas, trará uma explicação satisfatória ${ }^{7}$.

Dworkin adverte, porém, que o fato de o direito ser retratado, na metáfora da árvore, como um galho da moral não implica que o direito e a moral sejam sistemas indissociáveis. Assim, decisões proferidas por tribunais diferentes, que evidenciam distinções entre os sistemas de direito adotados por diferentes comunidades políticas, apresentam um papel determinante na fixação do que é o direito de cada comunidade, mas não têm a mesma relevância na definição do que é ou não justo. Portanto, embora o autor afirme, categoricamente, a existência de uma relação de

\footnotetext{
${ }^{3}$ POSNER, Richard A. The problematic of moral and legal theory. 3. ed. Harvard University Press, 2009. ${ }^{4}$ DWORKIN, Ronald. A justiça de toga, cit.

${ }^{5}$ Como bem observa Motta, é preciso redobrada cautela para que não se confunda, no contexto da obra de Dworkin, o direito com a moral. Não é de subordinação que trata a tese do direito como branch of morality. $\mathrm{O}$ autor adverte que toda a literatura dworkiniana é guiada por um alto grau de autonomia do direito. MOTTA, Francisco José Borges. Ronald Dworkin e a construção de uma teoria hermeneuticamente adequada da decisão jurídica democrática. 2014. 291f. Tese (Doutorado) - Universidade do Vale do Rio dos Sinos, Programa de Pós-Graduação em Direito, São Leopoldo, 2014. Disponível em: <http://www. repositorio.jesuita.org.br/handle/UNISINOS/3148>. Acesso em: 28 dez. 2016.

${ }^{6}$ DWORKIN, Ronald. A justiça de toga, cit.

${ }^{7}$ MOTTA, Francisco José Borges. op. cit.
} 
interatividade, circularidade, entre os dois sistemas, considera o direito e a justiça como domínios distintos ${ }^{8}$.

Por outro lado, o positivismo jurídico de $\operatorname{Hart}^{9}$ e Posner declara “a completa independência entre direito e moral". Sob este ponto de vista, o direito depende da aceitação (costumes e práticas) de uma determinada comunidade. Se uma regra é produzida de acordo com os padrões admitidos pela comunidade (por exemplo, pelo fato ter sido editada respeitando-se as diretrizes fixadas nas regras secundárias referidas), então pouco importa se é justa ou injusta: em todo caso, será considerada direito. De fato, como salienta $M o t t a^{10}$, a separação entre direito e moral é uma das características definidoras do positivismo jurídico ${ }^{11}$.

A atuação cada vez mais intensa dos juízes na área da saúde, atraindo para si a responsabilidade originariamente do Poder Executivo de viabilizar uma rede de serviços de saúde compatível com as necessidades da população, coloca a magistratura - e o Poder Judiciário como um todo - no centro de um caloroso debate que procura identificar os precisos contornos e limites da oponibilidade do direito à saúde em face dos órgãos públicos. Assim, a condução dos processos e as decisões proferidas nas reiteradas demandas em saúde passam a ser objeto das atenções - e da esperança - de boa parte da população, além do olhar crítico de estudiosa doutrina. Evidentemente, tamanha exposição tem como consequência inevitável a revelação das fragilidades do sistema judiciário, que abrangem desde a simples carência de recursos materiais e humanos até a complexa questão do processo decisório, foco de nossa reflexão neste trabalho.

Não obstante a teoria geral do processo enfatize como elementos imprescindíveis a uma prestação jurisdicional justa a imparcialidade e neutralidade dos magistrados, não há dúvidas de que estes são, de fato, fortemente influenciados por diversos fatores - internos e externos - e expressam suas convicções morais e políticas em suas deliberações. Partindo desse pressuposto e da evidência de que os magistrados, no âmbito de suas atribuições em demandas na área da saúde, são frequentemente instados a decidir com base em padrões distintos da tradicional submissão à legalidade, orientados por suas próprias convicções pessoais, acerca ora da política, ora da moral, este artigo busca analisar e compreender em que medida esses aspectos vêm, de fato, interferindo nas decisões judiciais em demandas voltadas a assegurar a tutela da saúde no âmbito dos tribunais federais do país.

\footnotetext{
${ }^{8}$ DWORKIN, Ronald. Justice for hedgehogs. Cambridge, Mass.; London: The Belknap Press of Harvard University Press, 2011. Disponível em: <http://www.academia.edu/9683075/Justice_for_Hedgehogs>. Acesso em: 28 dez. 2016.

${ }^{9}$ HART, Herbert L. A. O conceito de direito, 3. ed. Lisboa: Fundação Calouste Gulbekian, 1994.

${ }^{10}$ MOTTA, Francisco José Borges. op. cit.

${ }^{11} \mathrm{O}$ tema é aprofundado em ZEBULUM, José Carlos. Decisões judiciais em matéria de saúde: as conexões entre o direito e a moral. Cad. Ibero-Amer. Dir. Sanit., Brasília, v. 6, n. 1, p. 9-34, jan./mar. 2017. http:// dx.doi.org/10.17566/ciads.v6i1.355.
} 
Assim, com base na divergência acima apontada, interessa-nos verificar como decidem e fundamentam suas decisões os juízes nesses casos em que são desafiados em suas crenças, suas convicções e seus princípios morais. Isto porque, os juízes, ao proferirem suas decisões, conforme disposto no artigo 93, inciso IX, da Constituição Federal de 1988 (CF/1988), devem, efetivamente, fundamentar suas decisões, sob pena de nulidade; e, como adverte Manuel Atienza ${ }^{12}$, essa atividade deve ser lastreada por regras científicas. Portanto, se um juiz apresentar, como justificativa de sua decisão, suas convicções religiosas ou seu entendimento particular sobre o que é correto ou justo, não estará fundamentando nem justificando sua decisão, mas somente explicando-a. É evidente a dificuldade que o juiz experimenta ao tentar conferir um lastro técnico-jurídico, como impõe a Lei Maior, a uma decisão que proferiu, simplesmente, com base em suas convicções morais.

\section{Método}

Para atingir o objetivo acima descrito, realizamos uma pesquisa jurisprudencial de caráter documental que consistiu em um estudo seccional retrospectivo de decisões do Poder Judiciário federal, colhidas nas bases dos cinco tribunais federais do país ${ }^{13}$, adotando-se a técnica de análise de conteúdo. Selecionamos, inicialmente, três importantes questões com reconhecido potencial de desafiar as convicções morais dos magistrados e corriqueiramente enfrentadas em demandas judiciais de saúde no âmbito dos tribunais regionais federais (TRF) do país, a fim de verificarmos como os referidos tribunais vêm decidindo essas questões. A coleta dos dados jurisprudenciais foi realizada nas páginas eletrônicas de cada um dos tribunais regionais federais, tendo sido examinadas, para cada um dos cinco tribunais federais, todas as decisões proferidas a respeito de cada uma das questões nos últimos dois anos. Eis as questões.

Questão 1: paciente que apresenta quadro de doença que não vem respondendo aos tratamentos oferecidos pelo Sistema Único de Saúde (SUS) requer judicialmente, sob alegação de risco de vida comprovado em laudo médico, o fornecimento de medicamento(s) sem registro na Agência Nacional de Vigilância Sanitária (Anvisa). Neste caso, a pesquisa jurisprudencial realizada nas páginas eletrônicas de cada um dos tribunais regionais federais utilizou, como argumentos de busca, as seguintes expressões: "saúde", "medicamento", "registro" e "Anvisa".

Questão 2: paciente que se encontra em fila de espera para tratamento médico-cirúrgico em hospital público, mediante justificativa de comprovado agravamento em

\footnotetext{
${ }^{12}$ ATIENZA, Manuel. Razões do direito: teorias da argumentação jurídica. 3. ed. São Paulo: Landy, 2003.

${ }^{13}$ Neste artigo, nossas atenções voltam-se para a justiça federal. Como é cediço, as questões de saúde também são objeto de demandas nos tribunais estaduais. Assim, optamos por desenvolver pesquisa semelhante no âmbito da justiça estadual, cujos resultados serão apresentados e discutidos em outro artigo de nossa autoria, "Decisões judiciais na saúde, um campo propício para a interferência de convicções pessoais de cada juiz: uma análise da jurisprudência de quatro tribunais de justiça”, que se encontra no prelo.
} 
seu quadro clínico, busca provimento jurisdicional para obter prioridade de atendimento em relação aos demais. Para esta questão, a pesquisa jurisprudencial realizada nas páginas eletrônicas de cada um dos tribunais regionais federais utilizou, como argumentos de busca, as seguintes expressões: "saúde", "tratamento" e "fila". Aqui, a questão moral a ser decidida está em se o postulante que comprova a gravidade de seu quadro clínico deve ou não ser removido de sua posição na fila de espera por determinação judicial, ultrapassando, assim, aqueles que se encontram a sua frente aguardando o mesmo tratamento médico. Sabe-se que, regra geral, os hospitais especializados da rede pública organizam filas de espera de acordo com os procedimentos indicados para cada paciente. Existe, ao menos em algumas instituições públicas, uma ordem de preferência para os casos mais graves e outra para os casos rotineiros.

Questão 3: paciente portador de doença grave e rara requer que a União providencie e promova o custeio integral de tudo o que for necessário para que seja submetido a determinado tratamento de saúde -indisponível na rede de serviços do SUS e na rede privada -, prescrito em caráter de urgência conforme laudo médico e a ser realizado em hospital privado no exterior. A pesquisa jurisprudencial realizada nas páginas eletrônicas de cada um dos tribunais regionais federais utilizou, como argumentos de busca, as seguintes expressões: "tratamento", "médico" e "exterior". Como, para este caso, o número de situações encontradas inicialmente não se revelou suficiente para uma base de dados confiável, ampliamos o período de apuração para abranger decisões proferidas a partir de 2012.

A busca e a análise dos dados jurisprudenciais locais foram realizadas nos meses de dezembro de 2016 e janeiro de 2017 e permitiram uma abordagem comparativa sobre como essas questões vêm sendo enfrentadas pelos magistrados de cada um dos tribunais federais do país, para se concluir a respeito da ocorrência de conflitos morais experimentados pelos magistrados na apreciação dessas questões ${ }^{14}$. Quanto aos critérios de inclusão, compuseram o universo do estudo as decisões judiciais proferidas em agravos de instrumento, apelações, remessas necessárias, embargos infringentes e embargos de declaração durante o período de 01 de janeiro de 2015 a 30 de novembro de 2016, que contivessem na ementa os descritores eleitos para cada situação de interesse. Foram excluídos acórdãos que não abordassem especificamente as questões acima selecionadas.

\section{Resultados e discussão}

Adotando-se a metodologia acima descrita, para a Questão 1, retornaram, inicialmente, 629 documentos. Em uma segunda etapa, em que analisamos o inteiro teor do conteúdo de cada decisão, foram selecionados somente os documentos que

\footnotetext{
${ }^{14}$ Adotamos, aqui, metodologia semelhante àquela descrita por SIMAS, Luciana; VENTURA, Miriam; BAPTISTA, Michelly Ribeiro; LAROUZÉ, Bernard. A jurisprudência brasileira acerca da maternidade na prisão. Revista Direito GV, São Paulo, v. 11, n. 2, p. 547-572, dez. 2015. Disponível em: <http://bibliotecadigital.fgv. br/ojs/index.php/revdireitogv/article/view/58122/56587>. Acesso em: 02 jan. 2017. http://dx.doi. org/10.1590/1808-2432201524.
} 
diziam respeito especificamente ao objeto da pesquisa, excluindo-se, ainda, decisões que apareciam de forma repetida. Foram excluídos, portanto, 295 documentos, e restaram 334 documentos, que foram efetivamente utilizados em nossa análise. Em uma terceira etapa, analisamos com mais cuidado e reflexão o conteúdo de cada uma dessas decisões selecionadas, das quais 251 foram pelo deferimento do pedido, enquanto que 83 foram pelo indeferimento. $\mathrm{O}$ mesmo procedimento foi repetido para as questões 2 e 3 (Tabelas 1, 2, e 3 e Gráficos 1, 2 e 3).

Tabela 1. Questão 1: demandas judiciais para medicamentos sem registro na Anvisa

\begin{tabular}{lccccc}
\hline & $\begin{array}{c}\text { Número total } \\
\text { de documentos } \\
\text { retornados } \\
\text { inicialmente }\end{array}$ & $\begin{array}{c}\text { Número de } \\
\text { documentos } \\
\text { excluídos }\end{array}$ & $\begin{array}{c}\text { Número de } \\
\text { documentos } \\
\text { utilizados }\end{array}$ & $\begin{array}{c}\text { Número de } \\
\text { deferimentos }\end{array}$ & $\begin{array}{c}\text { Número de } \\
\text { indeferimentos }\end{array}$ \\
\hline TRF1 & 185 & 35 & 150 & 150 & 0 \\
TRF2 & 60 & 27 & 33 & 5 & 28 \\
TRF3 & 85 & 42 & 43 & 39 & 4 \\
TRF4 & 155 & 84 & 71 & 33 & 38 \\
TRF5 & 144 & 107 & 37 & 24 & 13 \\
\hline Totais & $\mathbf{6 2 9}$ & $\mathbf{2 9 5}$ & $\mathbf{3 3 4}$ & $\mathbf{2 5 1}$ & $\mathbf{8 3}$ \\
\hline
\end{tabular}

TRF1: Tribunal Regional Federal da $1^{\text {a }}$ Região; TRF2: Tribunal Regional Federal da $2^{\text {a }}$ Região; TRF3: Tribunal Regional Federal da $3^{\mathrm{a}}$ Região; TRF4: Tribunal Regional Federal da $4^{\mathrm{a}}$ Região; TRF5: Tribunal Regional Federal da $5^{\text {a }}$ Região
Deferimentos
Indeferimentos

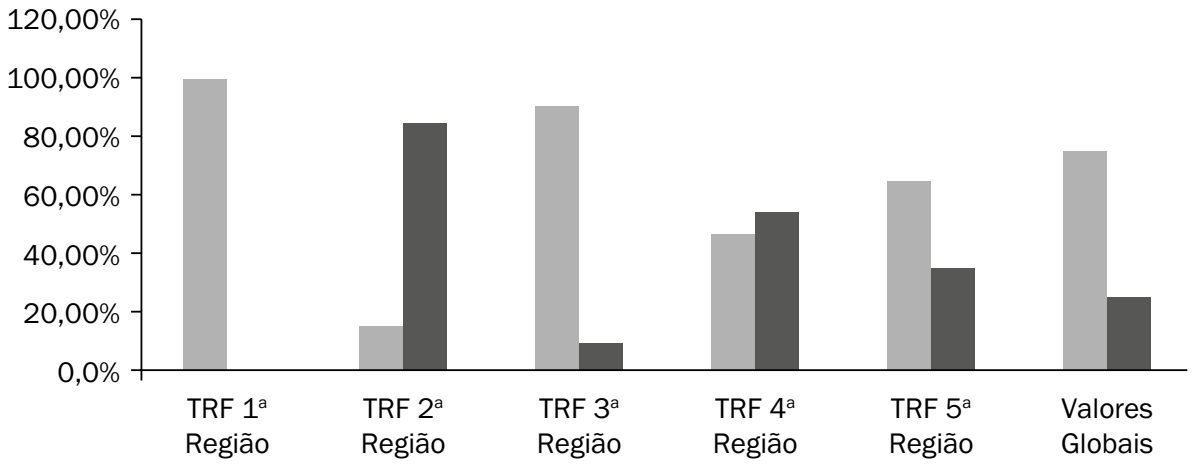

Gráfico 1. Questão 1: decisões deferidas e indeferidas para demandas judiciais de medicamentos sem registro na Anvisa

TRF1: Tribunal Regional Federal da $1^{\text {a }}$ Região; TRF2: Tribunal Regional Federal da $2^{\text {a }}$ Região; TRF3: Tribunal Regional Federal da $3^{a}$ Região; TRF4: Tribunal Regional Federal da 4ª Região; TRF5: Tribunal Regional Federal da $5^{\text {a }}$ Região 
Tabela 2. Questão 2: demandas judiciais solicitando prioridade de atendimento em hospital público

\begin{tabular}{lccccc}
\hline & $\begin{array}{c}\text { Número total } \\
\text { de documentos } \\
\text { retornados } \\
\text { inicialmente }\end{array}$ & $\begin{array}{c}\text { Número de } \\
\text { documentos } \\
\text { excluídos }\end{array}$ & $\begin{array}{c}\text { Número de } \\
\text { documentos } \\
\text { utilizados }\end{array}$ & $\begin{array}{c}\text { Número de } \\
\text { deferimentos }\end{array}$ & $\begin{array}{c}\text { Número de } \\
\text { indeferimentos }\end{array}$ \\
\hline TRF1 & 56 & 3 & 53 & 53 & 0 \\
TRF2 & 156 & 78 & 78 & 30 & 48 \\
TRF3 & 2 & 0 & 2 & 2 & 0 \\
TRF4 & 11 & 0 & 11 & 6 & 5 \\
TRF5 & 12 & 4 & 8 & 1 & 7 \\
\hline Totais & $\mathbf{2 3 7}$ & $\mathbf{8 5}$ & $\mathbf{1 5 2}$ & $\mathbf{9 2}$ & $\mathbf{6 0}$ \\
\hline
\end{tabular}

TRF1: Tribunal Regional Federal da $1^{\text {a }}$ Região; TRF2: Tribunal Regional Federal da $2^{\text {a }}$ Região; TRF3: Tribunal Regional Federal da $3^{\text {a }}$ Região; TRF4: Tribunal Regional Federal da $4^{\text {a }}$ Região; TRF5: Tribunal Regional Federal da $5^{\text {a }}$ Região

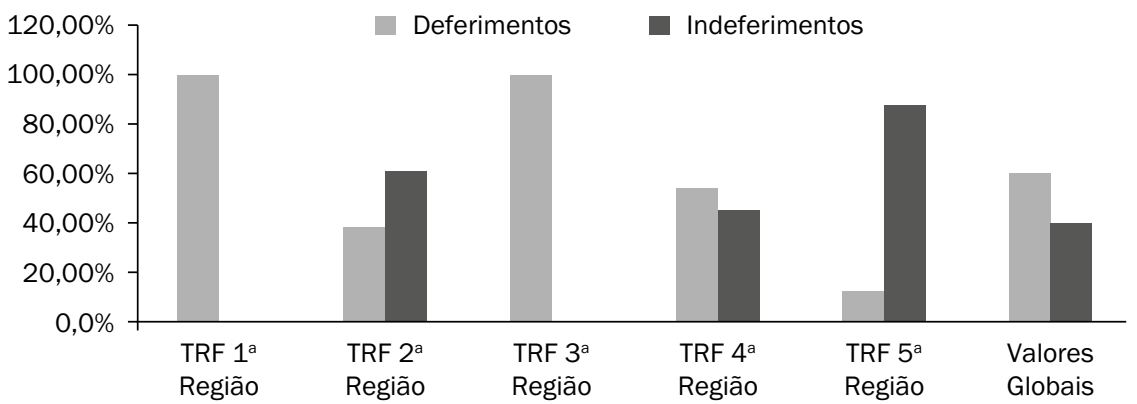

Gráfico 2. Questão 2: decisões deferidas e indeferidas para demandas judiciais solicitando prioridade de atendimento em hospital público

TRF1: Tribunal Regional Federal da $1^{\text {a }}$ Região; TRF2: Tribunal Regional Federal da $2^{\text {a }}$ Região; TRF3: Tribunal

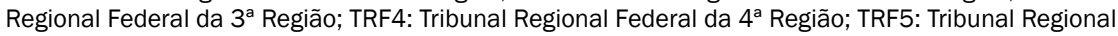
Federal da $5^{\mathrm{a}}$ Região

Tabela 3. Questão 3: demandas judiciais para tratamento de doença rara com prescrição médica feita no exterior

\begin{tabular}{lccccc}
\hline & $\begin{array}{c}\text { Número total } \\
\text { de documentos } \\
\text { retornados } \\
\text { inicialmente }\end{array}$ & $\begin{array}{c}\text { Número de } \\
\text { documentos } \\
\text { excluídos }\end{array}$ & $\begin{array}{c}\text { Número de } \\
\text { documentos } \\
\text { utilizados }\end{array}$ & $\begin{array}{c}\text { Número de } \\
\text { deferimentos }\end{array}$ & $\begin{array}{c}\text { Número de } \\
\text { indeferimentos }\end{array}$ \\
\hline TRF1 & 73 & 28 & 45 & 6 & 39 \\
TRF2 & 13 & 10 & 3 & 0 & 3 \\
TRF3 & 18 & 14 & 4 & 2 & 2 \\
TRF4 & 5 & 4 & 1 & 0 & 1 \\
TRF5 & 132 & 129 & 3 & 2 & 1 \\
\hline Totais & $\mathbf{2 4 1}$ & $\mathbf{1 8 5}$ & $\mathbf{5 6}$ & $\mathbf{1 0}$ & $\mathbf{4 6}$ \\
\hline
\end{tabular}

TRF1: Tribunal Regional Federal da $1^{\text {a }}$ Região; TRF2: Tribunal Regional Federal da $2^{\text {a }}$ Região; TRF3: Tribunal Regional Federal da $3^{\text {a }}$ Região; TRF4: Tribunal Regional Federal da $4^{\text {a }}$ Região; TRF5: Tribunal Regional Federal da $5^{\text {a }}$ Região 


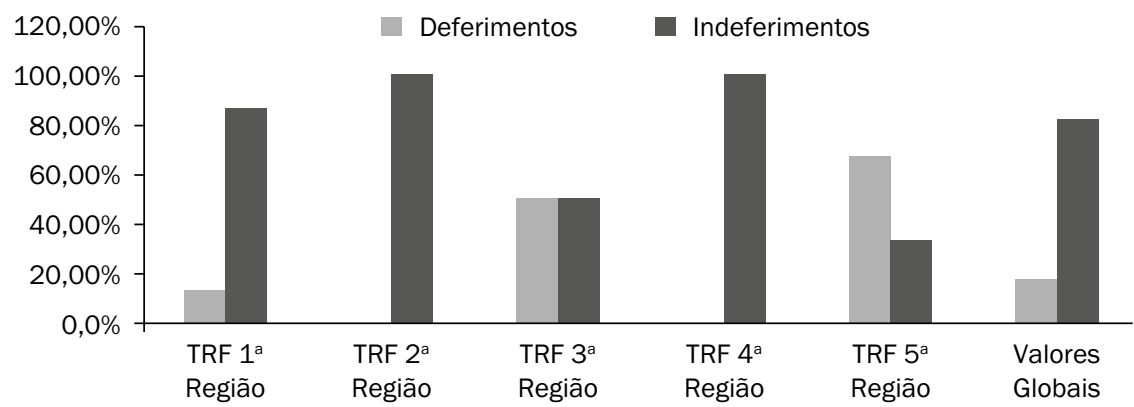

Gráfico 3. Questão 3: decisões deferidas e indeferidas para demandas judiciais para tratamento de doença rara com prescrição médica feita no exterior

TRF1: Tribunal Regional Federal da $1^{\text {a }}$ Região; TRF2: Tribunal Regional Federal da $2^{\text {a }}$ Região; TRF3: Tribunal Regional Federal da $3^{\mathrm{a}}$ Região; TRF4: Tribunal Regional Federal da $4^{\mathrm{a}}$ Região; TRF5: Tribunal Regional Federal da $5^{\text {a }}$ Região

No que diz respeito à Questão 1, verificamos, de plano, um evidente conteúdo moral como pano de fundo, vinculado à preservação da vida de uma pessoa que, de acordo com o parecer médico, está a depender de determinado(s) medicamento(s) que, em princípio, se revela $(\mathrm{m})$ eficaz(es) no tratamento da doença, mas que sequer se encontra $(\mathrm{m})$ registrado(s) na Anvisa - e, como se sabe, a lei veda, peremptoriamente, a dispensação, o pagamento, o ressarcimento ou o reembolso de medicamento e produto, nacional ou importado, sem registro na autarquia federal (art. 19-T, II, da Lei n. 8.080/1990) ${ }^{15}$.

A questão, se enfrentada pela lógica jurídica tradicional, não comportaria maiores digressões ou dificuldades, eis que a improcedência do pedido resultaria da simples aplicação da lei. Ocorre que nossa pesquisa revelou que todos os tribunais regionais federais, com apoio, inclusive, na jurisprudência de tribunais superiores, vêm determinando o fornecimento do(s) medicamento(s), a despeito da inexistência de registro na autarquia federal, claramente exigido pela lei, desde que conjugados os seguintes fatores, devidamente comprovados pela perícia:

(i) gravidade do quadro apresentado pelo paciente e a necessidade de utilização do medicamento em questão, normalmente em função da submissão a uma série de outros tratamentos anteriores que se mostraram ineficazes; e

\footnotetext{
${ }^{15}$ BRASIL. Lei n. 8.080, de 19 de setembro de 1990. Dispõe sobre as condições para a promoção, proteção e recuperação da saúde, a organização e o funcionamento dos serviços correspondentes e dá outras providências. Disponível em: <http://www.planalto.gov.br/ccivil_03/leis/L8080.htm>. Acesso em: 17 jun. 2018. Mas, como ressaltou o ministro Gilmar Mendes no julgamento da STA 175 AgR/CE: “[...] essa não é uma regra absoluta. Em casos excepcionais, a importação de medicamento não registrado poderá ser autorizada pela ANVISA. A Lei n. 9.782/99, que criou a Agência Nacional de Vigilância Sanitária (ANVISA), permite que ela dispense de registro medicamentos adquiridos por intermédio de organismos multilaterais internacionais, para uso de programas em saúde pública pelo Ministério da Saúde". (STF, STA 175 AgR/CE, Tribunal Pleno, Rel. Min. GILMAR MENDES (Presidente), julgamento: 17/03/2010, DJe 30/04/2010, p. 070.)
} 
(ii) eficácia já demonstrada pela medicação requerida no combate à doença que assola o paciente.

Na imensa maioria dos julgados analisados ${ }^{16}$, nos termos da metodologia já estabelecida, observamos que os juízes vêm deferindo os medicamentos requeridos a partir da mera enunciação dos fatores mencionados, sem apresentar, no entanto, qualquer argumentação de natureza jurídica a sustentar a não aplicação da lei ${ }^{1718} 19$.

Alguns julgados informaram ainda que o fato de o medicamento em tela não estar disponível na rede pública de saúde e não possuir registro na Anvisa não constitui óbice ao seu fornecimento, haja vista a aprovação do fármaco por entidades congêneres estrangeiras (como, por exemplo, nos Estados Unidos, a Food and Drug Administration - FDA), ou ainda, pelo fato de o relatório médico trazido pelo requerente estar fundado em estudo publicado por renomada revista médica.

Vale destacar, no entanto, que a pesquisa realizada na página eletrônica do TRF da $2^{\text {a }}$ Região revelou alguns julgamentos em sentido contrário, nos quais o fornecimento foi negado com base nos seguintes argumentos: (a) princípios da isonomia, da separação dos poderes e da reserva do possível; (b) limitações orçamentárias - nos casos em que se trata de medicamentos de alto custo; e (c) necessidade de novos exames para não pôr em risco a saúde do requerente.

Também é oportuno destacar julgamento proferido pelo TRF da $4^{\mathrm{a}}$ Região, em que a ação originária fora movida pelo Ministério Público Federal contra a União e o Estado do Paraná, requerendo o fornecimento de medicamento sem registro na

\footnotetext{
${ }^{16} \mathrm{~A}$ título de exemplo, confiram-se os seguintes julgados: TRF4 - QUARTA TURMA - AGRAVO DE INSTRUMENTO 5041197-36.2016.404.0000/SC - Relator DESEMBARGADOR FEDERAL LUÍS ALBERTO D'AZEVEDO AURVALLE - julgamento: 14/12/2016; TRF3 - QUARTA TURMA - AGRAVO DE INSTRUMENTO 571341/ SP - Relator DESEMBARGADOR FEDERAL MARCELO SARAIVA - julgamento: 03/08/2016 e-DJF3 Judicial: 18/08/2016; TRF3 - TERCEIRA TURMA - AGRAVO DE INSTRUMENTO 574047/SP - Relator DESEMBARGADOR FEDERAL ANTONIO CEDENHO - julgamento: 01/12/2016 e-DJF3 Judicial: 12/12/2016; TRF3 - QUARTA TURMA - AGRAVO DE INSTRUMENTO 577581/SP - Relator DESEMBARGADOR FEDERAL ANDRE NABARRETE - julgamento: 19/10/2016 e-DJF3 Judicial: 08/11/2016; TRF5 PRIMEIRA TURMA AGRAVO DE INSTRUMENTO $08054911720164050000 / S E$ - Relator DESEMBARGADOR FEDERAL RODRIGO VASCONCELOS COELHO DE ARAÚJO (Convocado) - julgamento: 06/12/2016.

${ }^{17}$ Verifique-se, a este título, o seguinte julgado: TRF5 TERCEIRA TURMA - AGRAVO DE INSTRUMENTO 08041011220164050000/SE - Relator DESEMBARGADOR FEDERAL PAULO MACHADO CORDEIRO julgamento: $23 / 11 / 2016$.

${ }^{18}$ Confiram-se os seguintes julgados: TRF2 - SÉTIMA TURMA ESPECIALIZADA - AGRAVO DE INSTRUMENTO 2016.00.00.008669-0 - Relator DESEMBARGADOR FEDERAL JOSÉ ANTONIO NEIVA - julgamento: 18/11/2016; TRF2 - SEXTA TURMA ESPECIALIZADA - AGRAVO DE INSTRUMENTO 2016.00.00.006741-5 - Relator DESEMBARGADOR FEDERAL NIZETE LOBATO CARMO - julgamento: 24/11/2016; TRF2 - SEXTA TURMA ESPECIALIZADA - AGRAVO DE INSTRUMENTO 2016.00.00.006741-5 - Relator DESEMBARGADOR FEDERAL NIZETE LOBATO CARMO - julgamento: 24/11/2016.

${ }^{19}$ TRF4 - TERCEIRA TURMA - EMBARGOS DE DECLARAÇÃO EM APELAÇÃO/REEXAME NECESSÁRIO n 5001455-60.2010.404.7001/PR - Relator DESEMBARGADOR FEDERAL CARLOS EDUARDO THOMPSON FLORES LENZ - julgamento: 27/11/2013. Em que pese o fato desta decisão específica estar fora do período adotado para a realização da coleta de dados, foi considerada em nossa pesquisa porque o feito prosseguiu, inclusive com decisão posterior proferida dentro do período em questão.
} 
Anvisa em favor de uma criança portadora de epilepsia focal sintomática e que já havia se submetido diversos tratamentos, inclusive no âmbito do SUS, com utilização de fármacos diferentes, sem obter resultado efetivo. Arguiu que somente a utilização do medicamento Keppra (levetiracetam) permitiu o controle, mesmo que parcial, das crises convulsivas, sendo inviável tratamento cirúrgico. Foi realizada perícia médica, que confirmou que a utilização exaustiva ao longo dos anos de drogas disponíveis no SUS, além de outras drogas específicas disponíveis no mercado, não lograram êxito no controle das crises da paciente, além do risco de óbito. Observamos que, neste caso em particular, o tribunal afastou a aplicação da lei, confirmando a decisão do juiz de primeiro grau, com base na seguinte argumentação:

[...] Negar-lhes o benefício da medicação constitui ato injusto se por justo tem-se a distribuição equânime de vantagens e encargos sociais. Perscrutando acerca do tema da justiça, Aristóteles principia o livro V da "Ética a Nicômaco": "No que tange à justiça e à injustiça temos que indagar precisamente a que tipos de ações elas concernem, em que sentido é a justiça uma mediania e entre quais extremos o ato justo é mediano" (ARISTÓTELES. Ética a Nicômaco. Trad. Edson Bini. Bauru: Edipro, 2007, 1126a1). Mais à frente, o filósofo no exame dos tipos de justiça registra que naquela distributiva o justo "é uma mediania entre dois extremos que são desproporcionais, uma vez que o proporcional é uma mediania e o justo é o proporcional" (Ét., 1131b10); e, se assim é, "o justo nesse sentido é, portanto, o proporcional e o injusto é aquilo que transgride a proporção" (Ét., 1131b15). Dilucida, ainda, o erudito Prof. Dr. Eduardo Bittar: "A injustiça, neste sentido, é o desigual, e corresponde ao recebimento de uma quantia menor de benefícios ou uma quantia maior de encargos que seriam realmente devidos a cada súdito. Ocorrendo a injustiça na distribuição, tendo-se uma escassez de benefícios ou um excesso de ônus, para uns, e um excesso de benefícios ou uma escassez de ônus, para outros, injusto é aquele que distribui, se consciente do mal que comete, uma vez que é deste que parte a iniciativa da ação de aquinhoamento e partição." (BITTAR, Eduardo Carlos Bianca. A justiça em Aristóteles. Rio de Janeiro: Forense Universitária, 1999, p.87) [...]

Uma simples leitura do julgado permite-nos concluir que o tribunal negou aplicação da lei como nos demais caso analisados, mas se utilizando de argumentação com forte apelo a elementos de conteúdo moral - e não jurídico -, como se conclui a partir das referências feitas ao "justo", ao "injusto", ao "desigual” e ao "proporcional", além das referências a fontes doutrinárias do campo da filosofia.

Tratando da Questão 2, a questão moral a ser decidida é se o postulante que comprova a gravidade de seu quadro clínico deve ou não ser removido de sua posição na fila de espera por determinação judicial, ultrapassando, assim, aqueles 
que se encontram a sua frente aguardando o mesmo tratamento médico. Sabe-se que, regra geral, os hospitais especializados da rede pública organizam filas de espera, de acordo com os procedimentos indicados para cada paciente. Existe, ao menos em algumas instituições públicas, uma ordem de preferência para os casos mais graves e outra para os casos rotineiros.

Ao analisarmos diversas decisões sobre o tema no âmbito das cortes selecionadas para a pesquisa, verificamos que, a princípio, há um consenso geral entre os juízes de que a fila deve ser rigorosamente obedecida, repudiando-se privilégios pessoais e se admitindo a interferência do Poder Judiciário apenas nos casos em que a espera represente grave risco para a saúde do paciente. Não havendo nos autos qualquer elemento de prova que justifique a mudança da posição do requerente na referida fila, evidenciando a gravidade do quadro, o tempo de espera e o risco para a saúde, os pedidos, em regra, vêm sendo indeferidos.

É interessante, no entanto, expor algumas variações de entendimento sobre o tema encontradas entre tribunais federais e, em alguns casos, dentro do mesmo tribunal. Por exemplo, no caso do TRF da $1^{\text {a }}$ região, há uma forte tendência ao deferimento dos pedidos, sendo reiteradas as decisões argumentando que "não há violação ao princípio da isonomia, em relação aos que se encontram em fila de espera, nas hipóteses em que [for] comprovado o agravamento do quadro clínico daquele que busca o provimento jurisdicional"20.

Já no TRF da 2a Região, registramos uma pequena oscilação da jurisprudência dentro do próprio tribunal. Em princípio, prevalecem, de forma muito evidente, decisões de indeferimento, sendo comum a argumentação de que, se não for comprovada a ilegitimidade da fila de espera ou situação excepcional do paciente que o diferencie dos demais que também aguardam atendimento, a imediata internação na rede pública, ou em hospital particular com custeio público, viola os princípios constitucionais da isonomia e da economicidade, caracterizando privilégio indevido à vista da necessidade dos outros pacientes que aguardam atendimento gratuito pelo SUS ${ }^{21}$.

Encontramos, no entanto, algumas decisões admitindo a prioridade de atendimento do requerente em relação aos demais integrantes da fila, uma delas argumentando que não se mostra razoável que, em caso de urgência, com risco

\footnotetext{
${ }^{20}$ Veja-se, por todos, o seguinte julgado: TRF1-SEXTA TURMA-APELAÇÃO CIVEL 0009700-52.2012.4.01.3803/ MG - Relator DESEMBARGADOR FEDERAL JIRAIR ARAM MEGUERIAN - julgamento: 07/11/2016 - e-DJF1: $17 / 11 / 2016$.

${ }^{21}$ Neste sentido, confiram-se os seguintes julgados: TRF2 - TERCEIRA TURMA - APELAÇÃO/REEXAME NECESSÁRIO 2013.51.01.115297-0 - Relatora DESEMBARGADORA FEDERAL NIZETE LOBATO CARMO julgamento: 07/11/2016; TRF2 - OITAVA TURMA ESPECIALIZADA - APELAÇÃO CIVEL 2008.51.01.0263818 - Relatora DESEMBARGADORA FEDERAL VERA LÚCIA LIMA - julgamento: 29/11/2016; TRF2 - QUINTA TURMA ESPECIALIZADA - AGRAVO DE INSTRUMENTO 2015.00.00.009479-7 - Relator DESEMBARGADOR FEDERAL RICARDO PERLINGEIRO - julgamento: 28/11/2016; e TRF2 - SÉTIMA TURMA ESPECIALIZADA REMESSA NECESSÁRIA 2014.51.01.141701-5 - Relator DESEMBARGADOR FEDERAL JOSÉ ANTONIO NEIVA - julgamento: 24/10/2016.
} 
de morte, o requerente seja obrigado a aguardar indefinidamente que outros casos supostamente mais graves sejam priorizados, eis que tal situação denotaria, na verdade, uma descabida desproporção entre o dimensionamento de recursos e a demanda existente no âmbito do SUS, a exigir providências enérgicas por parte de gestores e ordenadores de despesas ${ }^{22}$.

Enquanto que no TRF da $3^{\text {a }}$ Região, a pesquisa retornou apenas um julgado sobre o tema, que deferiu o pleito reiterando os argumentos que já identificamos em decisões de outros tribunais:

[...] Inexiste justificativa para uma pessoa aguardar em uma fila para atendimento odontológico por um período de quase dez anos, sofrendo de dores e sendo medicada por anos a fio com analgésicos orais e injetáveis, sem que a causa de sua moléstia seja tratada e possivelmente resolvida. Não há violação ao princípio da isonomia quando a paciente já aguarda há muito tempo em fila de espera, e diante do agravamento de sua saúde procura por guarida judicial (TRF3 - QUARTA TURMA - APELAÇÃO/REEXAME NECESSÁRIO - 1690182/SP - Relatora DESEMBARGADORA FEDERAL ALDA BASTO - julgamento: 05/02/2015 - e-DJF3 Judicial: 24/02/2015).

Observe-se, desde já, a divergência de entendimentos com o TRF da $1^{\text {a }}$ Região, que afasta, nesses casos, qualquer violação ao princípio da isonomia. Sugere-se, assim, que os juízes experimentam conflito moral ao apreciar essa questão ${ }^{23}$.

No TRF da $4^{\text {a }}$ Região, encontramos um certo equilíbrio entre decisões que admitem e que não admitem o avanço na fila por determinação judicial - restando, aqui também, evidenciada a divergência de entendimentos sobre a mesma questão, a evidenciar hipótese de conflito moral. Quanto às primeiras ${ }^{24}$, reitera-se o argumento de que "a espera desarrazoada em fila de espera para procedimento médico necessário e urgente, sem previsão concreta de que seja efetivado, equivale à ausência de fornecimento de tratamento médico pelo Poder Público”.

\footnotetext{
22TRF2 - OITAVA TURMA ESPECIALIZADA - AGRAVO DE INSTRUMENTO 2016.00.00.007083-9 - Relator DESEMBARGADOR FEDERAL MARCELO PEREIRA DA SILVA - julgamento: 22/11/2016

${ }^{23}$ No TRF da $3^{\text {a }}$ Região, encontramos apenas um caso que retratasse o enfrentamento dessa questão, tendo sido deferida a mudança de posição na fila com base em argumentação semelhante àquela adotada no âmbito do TRF da $1^{\text {a }}$ Região transcrita. Verifique-se o seguinte julgado: TRF3 - QUARTA TURMA - APELAÇÃO/ REEXAME NECESSÁRIO - 1690182/SP - Relator DESEMBARGADORA FEDERAL ALDA BASTO - julgamento: 05/02/2015 - e-DJF3 Judicial: 24/02/2015.

${ }^{24}$ Confiram-se os seguintes julgados: TRF4 - TERCEIRA TURMA - APELAÇÃO/REEXAME NECESSÁRIO $5007822-$ 83.2013.404.7102 - Relator DESEMBARGADOR FEDERAL FERNANDO QUADROS DA SILVA - julgamento: 07/10/2015; TRF4 - TERCEIRA TURMA - APELAÇÃO/REEXAME NECESSÁRIO 5007559-17.2014.404.7102 - Relator DESEMBARGADOR FEDERAL FERNANDO QUADROS DA SILVA - julgamento: 02/10/2015; e TRF4 - TERCEIRA TURMA - APELAÇÃO/REEXAME NECESSÁRIO 5004723-90.2013.404.7204 - Relator DESEMBARGADOR FEDERAL FERNANDO QUADROS DA SILVA - julgamento: 27/05/2015.
} 
Já quanto às decisões que não admitem, o argumento corrente é de que a intervenção judicial, nesses casos, deve ser excepcional, reservada a situações de risco de vida ou grave comprometimento da saúde daquele que a pleiteia, uma vez que a medida desfavorecerá os demais que aguardam o atendimento. Acrescenta-se, ainda, que "somente a espera desarrazoada em fila de espera para procedimento médico necessário e urgente, sem previsão concreta de que seja efetivado, equivale à ausência de fornecimento de tratamento médico pelo Poder Público" 25 .

Por derradeiro, no âmbito do TRF da $5^{\text {a }}$ Região, registramos, tal como ocorreu em relação ao TRF da $2^{\text {a }}$ Região, uma forte tendência ao indeferimento, não havendo grandes diferenças em relação à argumentação adotada.

Revela-se bem representativo do entendimento que vem sendo sufragado pelo tribunal o que segue:

[...] constata-se que, embora necessite da cirurgia, a autora deve respeitar a lista de espera do sistema público, que garante a isonomia de tratamento entre os cidadãos, inexistindo nos autos comprovação de que a Administração Pública esteja se recusando a realizar o procedimento médico postulado, ou de que esteja, no caso concreto, se portando com negligência na disponibilização do tratamento de que a autora necessita, situação injurídica que justificaria o acatamento de sua pretensão, já que, por outro lado, ela não poderia ser acorrentada à inércia das demais pessoas na busca por seus direitos. Em outros termos, se, por um lado, o direito subjetivo à saúde não se realiza pelo simples fato de o doente ser incorporado numa lista de espera; por outro lado, a desconsideração da lista de espera, ausentes fundadas razões para tanto (omissão administrativa no cumprimento de seu dever prestacional, risco de morte ou identificação de que a fila não tem sido respeitada), implica tratamento favorecido para uns em detrimento de todos os demais que aguardam a sua vez, também esses titulares do direito constitucional à saúde. (TRF5 - QUARTA TURMA - APELAÇÃO/REEXAME NECESSÁRIO 08052986520154058300/ PE - Relator DESEMBARGADOR FEDERAL RUBENS DE MENDONÇA CANUTO - julgamento: 08/06/2016).

A Questão 3 impõe aos juízes um evidente dilema moral, uma vez que terão que decidir entre a proteção da saúde no caso individual e a preservação do sistema como um todo, evitando a imposição de gastos excessivos que possam, no conjunto, comprometer o atendimento à coletividade. Trata-se de situações em que

\footnotetext{
${ }^{25}$ Nesse sentido, os seguintes julgados: TRF4 - QUARTA TURMA - AGRAVO DE INSTRUMENTO 5037282 76.2016.404.0000 - Relatora DESEMBARGADORA FEDERAL VIVIAN JOSETE PANTALEÃO CAMINHA julgamento: 23/11/2016; TRF4 - QUARTA TURMA-AGRAVO DE INSTRUMENTO 5020176-04.2016.404.0000 - Relatora DESEMBARGADORA FEDERAL VIVIAN JOSETE PANTALEÃO CAMINHA - julgamento: 31/08/2016; e TRF4 - QUARTA TURMA - APELAÇÃO CÍVEL 5010637-59.2013.404.7100 - Relatora DESEMBARGADORA FEDERAL MARGA INGE BARTH TESSLER - julgamento: 02/09/2015.
} 
o requerente, normalmente portador de doença cujo tratamento, no mais das vezes, não é oferecido pela rede pública ou privada no Brasil, requer judicialmente o custeio pelo poder público. Nos termos da Portaria n. 1.236, de 15 de outubro de 1993, do Ministério da Saúde, o tratamento médico no exterior de pacientes domiciliados no Brasil era admissível quando esgotadas todas as possibilidades de tratamento no nível do SUS. Ocorre que a referida portaria foi revogada pela Portaria n. 763, de 08 de abril de 1994, do Ministério da Saúde (Portaria MS n. 763/1994). Assim, atualmente, não há qualquer amparo legal para essa prática ${ }^{26}$.

No TRF da $1^{\text {a }}$ Região, registramos uma interessante decisão em agravo de instrumento interposto pela União ${ }^{27}$, que pleiteava a revogação de liminar concedida pelo juiz de primeiro grau nos autos de ação civil pública proposta pelo Ministério Público Federal. A decisão impugnada determinara o bloqueio do valor de R 130 mil, a fim de garantir o tratamento de aplicação de injeções de células-tronco na paciente na cidade de Bancoque, na Tailândia. $\mathrm{O}$ tribunal, argumentando que o direito à saúde é garantido pela Constituição de forma individual e coletiva (art. 196 da CF/1988), que o hipossuficiente não poderia custear o tratamento necessário sem prejuízo do próprio sustento e que havia sério risco de agravamento de sua saúde, manteve a decisão de primeiro grau, que havia bloqueado as verbas públicas para garantir o tratamento. Observe-se, assim, que, mesmo sem base legal, tanto o juiz de primeiro grau como o tribunal, com base em argumentação de cunho exclusivamente moral, garantiram o custeio do tratamento ${ }^{28},{ }^{29}$.

Em outro caso, o mesmo tribunal manteve decisão do juízo de primeiro grau, que havia reconhecido, em favor de pacientes portadores de patologia oftálmica, o direito à cirurgia de retinose pigmentar na República de Cuba, à custa do SUS, com fundamento na garantia constitucional à vida e à saúde. A decisão de primeiro grau fora proferida com base em entendimento que, na época, era amparado

\footnotetext{
${ }^{26}$ Trata-se de tratamentos extremamente caros que impõem ao erário gastos vultuosos, considerando-se que o poder público deverá custear outras despesas envolvidas, tais como passagens, estadia, medicamentos e alimentação, inclusive para eventuais acompanhantes. Impõe-se, assim, aos juízes um dilema moral, uma vez que terão que decidir entre a proteção da saúde no caso individual e a preservação do sistema como um todo, evitando a imposição de gastos excessivos que possam, no conjunto, comprometer o atendimento à coletividade.

${ }^{27}$ TRF1 - OITAVA TURMA ESPECIALIZADA - AGRAVO DE INSTRUMENTO 0013974-80.2016.4.01.0000 - Relator DESEMBARGADOR FEDERAL JIRAIR ARAM MEGUERIAN - julgamento: 19/05/2016.

${ }^{28}$ Por outro lado, identificamos duas decisões do mesmo tribunal em sentido totalmente contrário: negou o custeio do tratamento pelo poder público, arguindo a ausência de prova pré-constituída a sustentar a eficácia do tratamento e a impossibilidade de ele ser realizado no Brasil. Acrescentou-se, ainda, o reconhecimento, pelo STJ, da legalidade da Portaria MS n. 763/1994 mencionada que, segundo entendimento sufragado pelo tribunal, impede o financiamento pelo SUS de tratamento no exterior. Nesses casos, como vemos, a argumentação foi claramente técnico-jurídica. (TRF1 - QUINTA TURMA - APELAÇÃO CIVEL 0011110-64.2011.4.01.4100/RO - Relator DESEMBARGADOR FEDERAL JOÃO BATISTA MOREIRA julgamento: 26/11/2014 - e-DJF1 11/12/2014, p. 35; e TRF1 - SEXTA TURMA - APELAÇÃO EM MANDADO DE SEGURANÇA 0031006-98.2007.4.01.3400/DF - Relator DESEMBARGADOR FEDERAL KASSIO NUNES MARQUES - julgamento: 21/10/2013 - e-DJF1 08/11/2013, p. 589.)

${ }^{29}$ TRF4 - QUARTA TURMA - AGRAVO DE INSTRUMENTO 5029498-53.2013.404.0000 - Relatora DESEMBARGADORA FEDERAL VIVIAN JOSETE PANTALEÃO CAMINHA - julgamento: 18/02/2014.
} 
pela jurisprudência do STJ ${ }^{30}$. Mesmo que, posteriormente, o STJ tenha mudado seu entendimento, passando a considerar legítima, neste caso, a proibição de tratamento médico no exterior financiado pelo Ministério da Saúde em face da inexistência de comprovação científica quanto à eficácia do tratamento da retinose pigmentar em Cuba, o tribunal negou provimento ao recurso da União e manteve a decisão do juízo de primeiro grau, em respeito ao princípio da segurança jurídica e da teoria do fato consumado - argumentação puramente jurídica ${ }^{31}$.

Dentro de argumentações de cunho moral, na jurisprudência do TRF da $3^{\mathrm{a}}$ Região, encontramos um julgado em que o juiz de primeiro grau havia determinado que a União promovesse o custeio de neurocirurgia robótica para retirada de tumor cerebral benigno de uma criança, a ser realizada em determinado hospital de Paris, na França, indicado por médico especialista na área. $O$ tribunal manteve a decisão do juiz de primeiro grau, determinando o custeio, pela União, de todas as despesas, tais como passagens aéreas, hospedagem e alimentação para o agravado e ambos os pais, além de outras imposições. Apresentou argumentação exclusivamente de cunho moral, a evidenciar a existência de conflito desta natureza, uma vez que se referiu de forma vaga a princípios gerais do direito - como a inexistência de vulneração aos princípios da legalidade, da isonomia ou da separação dos poderes diante das particularidades do caso concreto -, à menoridade do autor e à impossibilidade de os pais arcarem com os custos ${ }^{32}$.

Mostrando até onde pode chegar o ônus financeiro imposto ao ente público nessas situações, no TRF da $2^{\text {a }}$ Região, registramos um caso que bem denota Trata-se de processo em que o juiz de primeiro grau havia antecipado os efeitos da tutela para determinar que a União providenciasse e promovesse o custeio, de forma integral, de tudo o que fosse necessário para que a autora fosse submetida à cirurgia de transplante de intestino e aos respectivos tratamentos de que necessitasse junto ao hospital Jackson Memorial Medical, situado em Miami (Estados Unidos), durante o tempo que se fizesse necessário, inclusive com o tratamento homecare que a equipe médica daquele hospital recomendasse, respeitando-se a fila norte-americana e seus critérios de espera pelo transplante. Estabeleceu, ainda, que a União deveria providenciar a remoção via aérea da cidade do Rio de Janeiro/RJ, com aeronave equipada com tudo o que fosse necessário à manutenção da vida da autora durante o traslado (UTI médica), sem prejuízo da remoção rodoviária até o aeroporto, com os mesmos cuidados, sendo que a remoção deveria ser realizada em relação à autora

\footnotetext{
30Vide REsp. 353147/DF, SEGUNDA TURMA, Relator MINISTRO FRANCIULLI NETTO, julgamento: 15/10/2002 - DJ 18/08/2003.

${ }^{31}$ TRF3 - QUARTA TURMA - APELAÇÃO CIVEL 0025323-50.2002.4.03.6100/SP - Relator DESEMBARGADOR FEDERAL MARCELO SARAIVA - julgamento: 06/07/2016 - e-DJF3 Judicial: 20/07/2016

${ }^{32}$ TRF3 - SEXTA TURMA - AGRAVO DE INSTRUMENTO 0013099-56.2016.4.03.0000/SP - Relatora DESEMBARGADORA FEDERAL CONSUELO YOSHIDA - julgamento: 20/10/2016 - e-DJF3 Judicial: 07/11/2016
} 
e ao seu marido. O tribunal, atendendo a pedido da União, cassou decisão que havia sido proferida pelo juiz de primeiro grau, deferindo o tratamento médico requerido pela autora, argumentando que somente o procedimento cirúrgico alcançaria o expressivo montante de um milhão de reais, circunstância que não poderia ser desconsiderada pelo julgador, ante os limites orçamentários aos quais a administração pública deve respeito. Ressaltou também que a decisão agravada, contendo o comando para que a recorrida fosse submetida, imediatamente, à cirurgia em tela, configurava medida dotada de caráter de irreversibilidade, no tocante ao custeio de todo o tratamento pela União, ferindo o Código de Processo Civil. Temos assim, um argumento de cunho político - a preservação do erário - e outro de cunho jurídico - a irreversibilidade do provimento ${ }^{33}$.

No TRF da $4^{\text {a }}$ Região, identificamos apenas um caso $^{34}$ : o tribunal, em recurso de agravo de instrumento, manteve decisão de primeiro grau que havia indeferido antecipação dos efeitos da tutela, inadmitindo o custeio pelos cofres públicos de tratamento médico no exterior (utilização de células-tronco para tratamento de patologia). Em sua argumentação, ponderou que o tratamento requerido ainda era experimental e incipiente, havendo fundadas dúvidas a respeito de sua eficácia; o custo seria elevadíssimo e suportado pelos cofres públicos; além do fato de a medida pleiteada ser totalmente satisfativa, pois, realizado o tratamento no exterior, não poderia ser revertida em um momento processual posterior. Assim, o tribunal se utilizou de um argumento político - a preservação do erário - e de dois argumentos técnico-jurídicos - tratamento ainda experimental e irreversibilidade do provimento.

No âmbito do TRF da $5^{\text {a }}$ Região, também houve um único caso ${ }^{35}$, de natureza semelhante à do caso apreciado pelo TRF da $4^{\text {a }}$ Região acima tratado, mas agora com desfecho totalmente distinto. Na situação em pauta, a decisão de primeiro grau havia deferido pedido de antecipação dos efeitos da tutela, formulado pela autora, para determinar à União, ao Estado do Ceará e ao Município de Fortaleza que custeassem o tratamento médico com células-tronco, bem como o transporte da autora e de seu filho para a realização do procedimento no exterior. Em agravo de instrumento interposto pela Fazenda Pública, a decisão de primeiro grau foi integralmente mantida com base em argumentação muito fraca do ponto de vista

\footnotetext{
${ }^{33}$ TRF2 - OITAVA TURMA ESPECIALIZADA - AGRAVO DE INSTRUMENTO 2015.00.00.010086-4 - Relatora DESEMBARGADORA FEDERAL VERA LÚCIA LIMA - julgamento: 25/01/2016). Em outro caso de semelhante natureza, o mesmo tribunal negou o custeio de tratamento no exterior pelo ente público ao argumento técnico-jurídico de que "a efetivação do direito constitucional à saúde é limitada ao alcance das ações e serviços públicos implementados pelo Estado dentro do chamado sistema único, no qual não estão inseridos tratamentos disponibilizados fora do território nacional" (TRF2 - OITAVA TURMA ESPECIALIZADA - AGRAVO DE INSTRUMENTO 2016.00.00.003093-3 - Relator DESEMBARGADOR FEDERAL MARCELO PEREIRA DA SILVA - julgamento: 21/06/2016).

${ }^{34}$ TRF4 - QUARTA TURMA - AGRAVO DE INSTRUMENTO 5029498-53.2013.404.0000 - Relatora DESEMBARGADORA FEDERAL VIVIAN JOSETE PANTALEÃO CAMINHA - julgamento: 18/02/2014.

${ }^{35}$ TRF5-TERCEIRA TURMA-AGRAVO DE INSTRUMENTO $00125347720124050000 / C E$ - Relator DESEMBARGADOR FEDERAL GERALDO APOLIANO - julgamento: 10/01/2013 - TRF5 (DJE): 28/01/2013 - p. 243.
} 
jurídico: o material probatório era suficiente a configurar a necessidade de atendimento da pretensão, na medida em que se cuidava de necessidade especialmente legítima, e constitucionalmente protegida, uma vez que se tratava de assegurar o direito social à saúde e, em análise última, o direito fundamental à vida; a imposição, pelo Poder Judiciário, da concretização do direito à vida não implicaria em ofensa aos princípios da isonomia e impessoalidade ou à separação dos poderes; a teoria da reserva do possível apenas seria aplicável quando demonstrado, efetivamente, $o$ comprometimento do orçamento pelo fornecimento do medicamento.

Vê-se que a argumentação foi calcada em princípios gerais do direito de forma vaga, excessivamente genérica, sem que tenha sido utilizada qualquer técnica de ponderação entre os princípios utilizados e sem maiores preocupações com as peculiaridades do caso concreto, omitindo-se o tribunal sobre a irreversibilidade do provimento, o caráter experimental e a onerosidade do tratamento.

\section{Considerações finais}

Nos três casos acima discriminados, verificamos que, em diversas situações, os magistrados, possivelmente premidos por suas convicções pessoais, não se sentiram "confortáveis" em adotar a solução eventualmente apontada pela simples aplicação da lei. Experimentaram, portanto, situações de conflito, uma vez que decidiram mais em função de sua sensibilidade do que com base em seus vastos conhecimentos sobre as leis e a ordem jurídica. Daí resultou uma evidente dificuldade em fundamentar a decisão com base em preceitos técnico-jurídicos (legislação ou princípios de direito, ainda que não positivados). Verificamos, desta feita, que a argumentação utilizada para fundamentar tais decisões se afastou, invariavelmente, do tradicional discurso técnico-jurídico, revelando o uso das seguintes técnicas por parte dos magistrados:

(i) utilização de expressões de menor densidade jurídica, a expressar uma avaliação puramente subjetiva, tais como "é razoável", "não é proporcional", "é justo" etc.;

(ii) adoção de critérios que mais expressam sentimentos humanitários de solidariedade, justiça e preocupação com o bem-estar do próximo e que, embora louváveis, se revelam distantes de qualquer acepção técnico-jurídica. Nessa linha, algumas decisões são justificadas pelo intuito de proteger os mais pobres, as crianças, os portadores de deficiência etc.;

(iii) a simples utilização de princípios gerais do direito de forma vaga e imprecisa, que aparecem como formulações genéricas hábeis a justificar toda e qualquer decisão, sem que tenha sido utilizada qualquer técnica de ponderação e sem que tenham sido efetivamente enfrentadas as peculiaridades do caso concreto; $\mathrm{e}$

(iv)o recurso a fontes doutrinárias que militam no campo da filosofia, estranhas ao direito enquanto disciplina. 
Além desses indícios observados na argumentação utilizada pelos juízes, a existência de conflitos morais experimentados pelos juízes também restou evidenciada a partir da verificação de soluções radicalmente diferentes para casos idênticos. É bem verdade que uma certa oscilação da jurisprudência, que decorre de diferentes interpretações conferidas à lei, é sempre esperada e considerada normal, mas, diante de questões morais - em que cada magistrado decidirá de acordo com seus princípios e conviç̧ões pessoais, que nem sempre coincidirão com aqueles adotados por seus pares -, a divergência deverá assumir uma amplitude ainda mais significativa.

É o que se verifica, por exemplo, a partir dos resultados estampados no Gráfico 1. Com efeito, no enfrentamento da Questão 1, verifica-se uma intensa divergência de entendimentos entre tribunais federais sobre a mesma questão de direito, pois, enquanto nos TRF da $1^{\text {a }}$ e da $3^{\text {a }}$ Regiões prevalecem de forma evidente decisões pelo deferimento do medicamento não registrado na Anvisa, no TRF da $2^{\text {a }}$ Região prevalecem decisões em sentido contrário. Por outro lado, o resultado obtido para o TRF da $4^{a}$ Região indica uma forte divergência interna, ou seja, entre magistrados do mesmo tribunal.

A mesma conclusão pode ser obtida a partir da análise dos resultados indicados no Gráfico 3. Verifica-se que a Questão 3 foi objeto de intensa controvérsia entre magistrados do TRF da $3^{\text {a }}$ Região, ao mesmo tempo em que foi decidida sem qualquer divergência entre magistrados do TRF da $2^{\text {a }}$ Região.

Ainda em relação à Questão 1, há que ressaltar, ainda, a existência de uma importante questão jurídica que os tribunais vêm se eximindo de enfrentar: a não aplicação da lei que exige o registro na Anvisa - fora dos casos excepcionais em que o registro pode ser dispensado, evidentemente. Os juízes, de uma forma geral, só devem negar aplicação de lei em vigor se a considerarem inconstitucional, o que deve constar, expressamente, dos fundamentos da decisão. Em se tratando de decisão de tribunal, como no caso, deve-se, inclusive, instaurar o incidente de arguição de inconstitucionalidade previsto no Código de Processo Civil ${ }^{36}$ (arts. 948 e 949), como, aliás, exige a Súmula Vinculante n. 10, do Supremo Tribunal Federal (STF):

Viola a cláusula de reserva de plenário (CF, artigo 97) a decisão de órgão fracionário de Tribunal que embora não declare expressamente a inconstitucionalidade de lei ou ato normativo do poder público, afasta sua incidência, no todo ou em parte ${ }^{37}$.

Esse procedimento não foi observado em nenhum dos casos em que o fornecimento fora concedido ao arrepio da lei, o que corrobora a ideia de que as

\footnotetext{
${ }^{36}$ BRASIL. Lei n. 13.105, de 16 de março de 2015. Código de Processo Civil. Disponível em: <http://www. planalto.gov.br/ccivil_03/_ato2015-2018/2015/lei/l13105.htm>. Acesso em: 17 jun. 2018.

${ }^{37}$ SUPREMO TRIBUNAL FEDERAL. Súmula Vinculante. Disponivel em: <http://www.stf.jus.br/portal/cms/ verTexto.asp?servico=jurisprudenciaSumulaVinculante>. Acesso em: 26 dez. 2016.
} 
deliberações vêm ocorrendo no contexto de conflitos morais. Com efeito, a cláusula de reserva de plenário impõe ao tribunal que eventualmente decidir afastando a lei por considerá-la incompatível com as regras ou os princípios constitucionais que adote o procedimento previsto na legislação processual acima referida, o que não foi observado em nenhum dos casos analisados. As decisões assim proferidas, além de afrontarem a Constituição, violam o entendimento sufragado pela corte suprema na súmula vinculante acima transcrita, o que não pode ser considerado como uma técnica ajustada aos padrões estabelecidos, ao menos sob o ponto de vista jurídico.

Em relação à Questão 2 objeto de nossa análise, os resultados obtidos também sugerem que juízes vêm experimentando um conflito interno ao apreciá-la. Chegamos a esta conclusão a partir da natureza da argumentação apresentada na fundamentação das diversas decisões examinadas, sendo frequentes a utilização de princípios gerais do direito, sempre de forma vaga; a utilização de expressões que demonstram avaliações puramente subjetivas e que não permitem a identificação de um parâmetro seguro a ser adotado, como razão de decidir em um ou em outro sentido, tais como "espera desarrazoada", "privilégio indevido", etc.; a própria divergência de entendimentos entre os tribunais - neste particular, restou muito clara a divergência de entendimentos entre os TRF da $2^{\text {a }}$ e da $5^{a}$ Regiões, que vêm indeferindo reiteradamente os pedidos desta natureza, com o TRF da $1^{\text {a }}$ Região, que vem adotando, como regra, o deferimento do pleito - e entre magistrados integrantes do mesmo tribunal - como restou bem registrado a partir dos resultados obtidos com a pesquisa realizada na página eletrônica do TRF da $4^{\mathrm{a}}$ Região -, o que corrobora a tese de que as decisões se sustentam em padrões morais de caráter pessoal, que variam, como vimos, de pessoa para pessoa e, portanto, de juiz para juiz.

Por derradeiro, os resultados obtidos em relação à Questão 3 analisada demonstram que as decisões que indeferiram o tratamento no exterior, em todos os tribunais, ou se embasaram em argumentos técnico-jurídicos - ausência de prova pré-constituída a sustentar a eficácia do tratamento e da impossibilidade de ele ser realizado no Brasil; a legalidade da Portaria MS n. 763/1994; e a irreversibilidade do provimento concessivo, que contraria norma processual - ou em argumento político - o enorme dispêndio de recursos públicos. Por outro lado, as decisões que deferiram o tratamento se utilizaram de argumentação exclusivamente moral - a impossibilidade de o hipossuficiente custear o tratamento necessário; a referência vaga a princípios gerais do direito; e a eventual menoridade do autor. Essa evidência sugere que os juízes que vêm deferindo o tratamento experimentam, de fato, conflito moral, o que não vem ocorrendo na hipótese de indeferimento - até porque esta orientação se apoia claramente na legislação, o que, ao menos em tese, deixa os juízes em posição mais confortável para decidir. Por outro lado, o conflito moral ficou muito bem caracterizado, nestes casos, quando evidenciamos que uma questão idêntica - utilização de células-tronco para tratamento de patologia - obteve decisões absolutamente divergentes, eis que o mesmo tratamento foi deferido pelos TRF da $1^{\mathrm{a}}$ e da $5^{\mathrm{a}}$ Regiões, mas indeferido pelo TRF da $4^{\mathrm{a}}$ Região. 


\section{Referências}

ATIENZA, Manuel. Razões do direito: teorias da argumentação jurídica. 3. ed. São Paulo: Landy, 2003.

DIAS, Maria Clara. Sobre nós. Expandindo as fronteiras da moralidade. RJ: Pirilampo, 2016.

DWORKIN, Ronald. A justiça de toga. São Paulo: Martins Fontes Editora, 2010.

. Justice for hedgehogs. Cambridge, Massachusetts, London: The Belknap Press of Harvard University Press, 2011. Disponível em: <http://www.academia.edu/9683075/ Justice_for_Hedgehogs>. Acesso em: 28 dez. 2016.

HART, Herbert L.A. O Conceito de direito, 3.ed. Lisboa: Fundação Calouste Gulbekian, 1994.

MOTTA, Francisco José Borges. Ronald Dworkin e a construção de uma teoria hermeneuticamente adequada da decisão jurídica democrática. Tese (doutorado). 2014. $291 \mathrm{f}$. Universidade do Vale do Rio dos Sinos, Programa de Pós-Graduação em Direito, São Leopoldo, 2014. Disponível em: < http://www.repositorio.jesuita.org.br/handle/UNISINOS/3148>. Acesso em: 28 dez. 2016.

POSNER, Richard A. The problematic of moral and legal theory. 3. ed. Harvard University Press, 2009.

SIMAS, Luciana; VENTURA, Miriam; BAPTISTA, Michelly Ribeiro; LAROUZÉ, Bernard. A jurisprudência brasileira acerca da maternidade na prisão. Revista Direito GV, São Paulo, v.11, n. 2, p. 547-572, dez. 2015. Disponível em: <http://bibliotecadigital.fgv.br/ojs/ index.php/revdireitogv/article/view/58122/56587>. Acesso em: 02 Jan. 2017. http://dx.doi. org/10.1590/1808-2432201524.

ZEBULUM, José Carlos. Decisões judiciais em matéria de saúde: as conexões entre o direito e a moral. Revista Cadernos Ibero-Americanos de Direito Sanitário. Brasil, 6 (1): 9-34, jan./mar. 2017.

José Carlos Zebulum - Doutorando em Saúde Pública pela Universidade Federal do Rio de Janeiro (UFRJ); mestre em Direito pela Universidade do Estado do Rio de Janeiro (UERJ); graduado em Direito pela UERJ; graduado em Engenharia Naval pela Universidade de São Paulo. Professor da Fundação Educacional Serra dos Órgãos. Juiz Federal do Rio de Janeiro. Rio de Janeiro/RJ, Brasil.E-mail: jcarloszebulum@gmail.com 